\title{
Socialization of Organic and Inorganic Waste Segregation as a Form of Environmental Concern during the Covid-19 Pandemic in Public Elementary School (SDN)10 Ciamis, Indonesia
}

\author{
Abdul Zamal Sigit \\ Department of Management, Universitas Garut, Garut, Indonesia \\ *Corresponding author email: sigitabdulzamal@gmail.com
}

\begin{abstract}
Community Service is one of the Tri Dharma of Higher Education, especially at Garut University, it is hoped that with this community service the existence of universities can contribute to the development of scientific application to the community. Efforts to protect the surrounding environment must start from oneself by doing small things, educating students about environmental problems due to landfills is needed to raise students' awareness so that they are more concerned with the surrounding environment. Active participation of students can be done in a culture of disposing of waste in its place. However, because of the many categories of waste that exist, it is necessary to educate students about the types of waste, namely; organic, inorganic and B3 waste (hazardous and toxic materials) and their handling. This community service activity method uses the method of delivering socialization material with counseling techniques, questions and answers, quizzes, and by adding games. The results of the research carried out were able to make students leave the old way of just throwing garbage away, but also provide education and familiarize students to sort, select, and categorize waste as well as develop a waste bank so that it has economic value. If this is done, the practice of processing and utilizing waste becomes a real step in managing waste.
\end{abstract}

Keywords: Socialization, Waste Sorting, Reduce, Reuse, Recycle

\section{Introduction}

Garbage is a waste product from human activities which contains various toxic materials such as heavy metals, insecticides (Pandebesie et al., 2019; Sarli et al., 2107). So, the humans who are in direct contact with waste can be at risk of experiencing various disorders such as digestive and respiratory which are dangerous. Therefore, handling a lot of waste and piling up, needs high caution, especially for garbage collectors who hold or experience direct contact with garbage (Khalil et al., 2019; Meidiana and Gamse, 2010; Gusti, 2016; Dhokhikah et al., 2015).

Waste sorting should be done from the source, and can be classified simply into organic and inorganic waste. Providing education related to waste sorting is one of the keys to the success of processing waste into something more useful (Sekito et al., 2013; Posmaningsih et al., 2018). In the integrated waste management plan, it is necessary to have better waste management methods, increase the participation of relevant institutions in increasing the efficiency and effectiveness of waste management, as well as increasing community empowerment. In the process of integrated waste processing towards Zero Waste, it must always support environmentally friendly conditions and the surrounding community (Raharjo et al., 2017; Sasaki et al., 2014; Singer et al., 2019).

According to Law number 18 of 2008 it is stated that waste is the residue of human daily activities or natural processes in solid form. Improper and improper waste management will cause various losses, including bad smells, disturbing beauty, causing flooding, damage to environmental sanitation, increasing climate warming, and the emergence of various diseases (Phan Hoang and Kato, 2021; Paul et al., 2012). Community involvement in waste management plays an important role because participation is a tool to obtain information about the conditions, needs and attitudes of the local community (Chakrabarti et al., 2009).

The waste will increase if there is no preventive action and good management, the number of processes carried out makes the landfilling of waste higher, therefore a process is needed that can process something that is not used into useful goods. some principles that need to be applied (Kim et al., 2007; Ryu et al., 2001). The following are the principles that can be applied in waste processing, these principles are known as the 4Rs including Reducing, minimizing the goods or materials we use; Reuse, sort out items that can be reused, avoid using disposable items; 
Recycle, reuse items that are no longer useful; Replace, examine the items we use every day by replacing items that can only be used once with items that are more durable.

Waste is divided into 3 types, namely organic, inorganic, and B3 (Hazardous and Toxic Materials). Each type of waste has a different character and different processing methods, including: organic waste originating from living things, whether humans, animals, or plants. Organic waste itself is divided into wet organic waste, which is waste that has a fairly high-water content. Examples include fruit peels and vegetable scraps. Then dry organic waste is another organic material with a small water content. Examples of dry organic waste include paper, wood or tree branches, and dry leaves. Then Inorganic Waste is waste produced from non-biological materials, either in the form of synthetic products or the result of technological processes for processing mining materials or natural resources and cannot be decomposed by nature, for example: plastic bottles, plastic bags and cans. B3 Waste (Hazardous and Toxic Materials) is any waste that contains hazardous or toxic materials due to their nature, concentration and amount, either directly or indirectly can damage the environment or endanger human health (Grodzińska-Jurczak, 2003).

According to the Law of the Republic of Indonesia No. 18 of 2008 concerning Waste Management, B3 waste is specific waste which includes: waste containing hazardous and toxic materials, waste containing B3 waste, waste arising from disasters, demolition of building debris, technologically unprocessed waste and waste arising periodically. The education regarding the types of waste and waste sorting is delivered to high school students in the hope that they will be able to carry out further handling of waste in their school environment so that they are able to overcome the further impacts of waste (Derqui and Fernandez, 2017).

The socialization was given to school students because they saw the importance of the active role of students in starting actions to prevent the accumulation of garbage around them. By providing education, it is hoped that students will be able to transmit good habits to the people around them, both family, friends and their environment by disposing of waste by sorting it. An understanding of the obligation to protect the surrounding environment must start from oneself by doing small things. Education for high school students about environmental problems due to landfills is needed to raise students' awareness so that they are more concerned with the surrounding environment. Active participation of students can be done in a culture of disposing of waste in its place (Moh, 2017).

However, because of the many categories of waste that exist, it is necessary to educate students about the types of waste, namely; organic, inorganic and B3 waste (hazardous and toxic materials) and their handling. Students must be socialized to leave the old way of just throwing garbage away, but also provide education and familiarize students to sort, select, and categorize waste as well as develop a waste bank so that it has economic value. If this is done, the practice of processing and utilizing waste becomes a real step in managing waste. These small habits will later be transmitted in the family and the surrounding community which allows reducing environmental problems caused by waste.

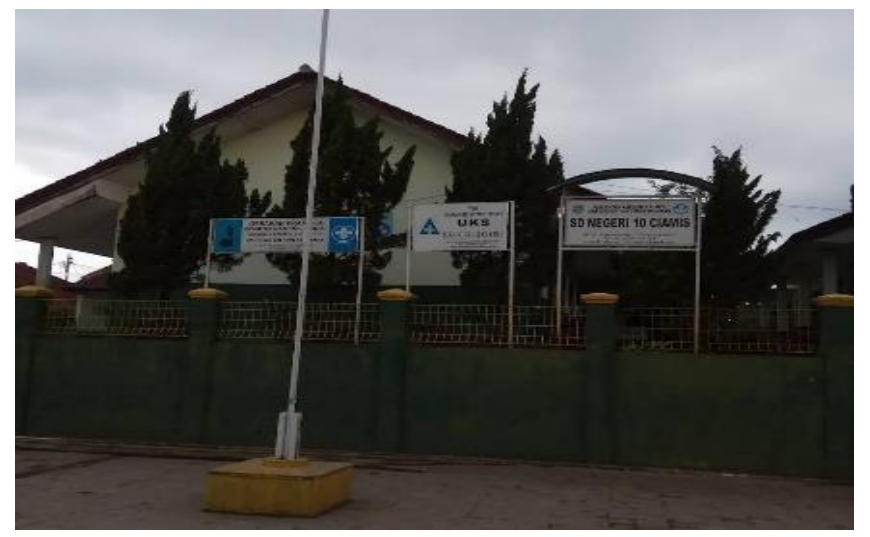

Figure 1. SDN 10 Ciamis

This community service aims to assist SDN 10 Ciamis in sorting organic, inorganic and B3 waste (See Figure 1). Several things the team did in this community service activity were teaching students to be able to process and utilize waste which is a real step in managing waste. These small habits will later be transmitted within the family and the surrounding community which allows reducing environmental problems caused by waste providing socialization of understanding to be able to distinguish organic, inorganic and B3 waste for a brighter future.

\section{Methodology}

The implementation of the service activity will take place on February 21, 2021 at Jln Ir. H Juanda No. 272 Ciamis District, Ciamis Regency, West Java, Indonesia (See Figure 2). 


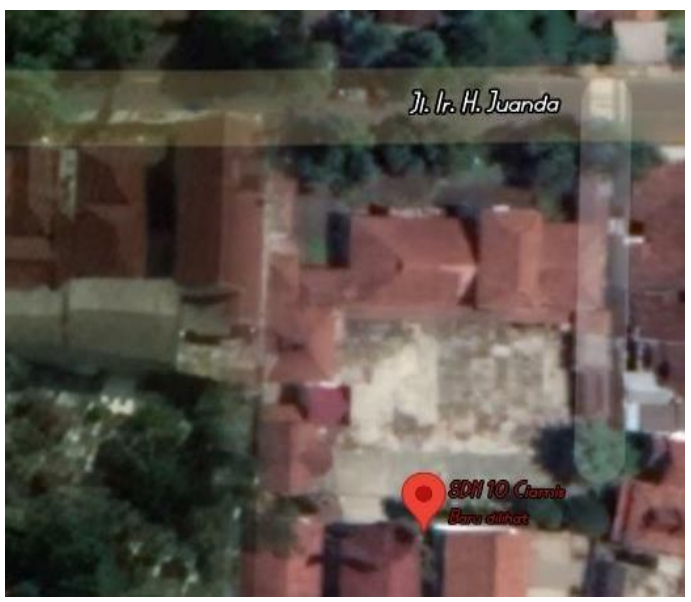

Figure 2 Map Location SDN 10 Ciamis

The method used in the implementation of community service activities is socialization with counseling techniques in the form of lectures or presenting material in the form of theories and animated videos related to waste sorting, questions and answers, creations, and games, including:

- Observation Stage

This activity is carried out as the beginning of the activity with the aim of obtaining a description of the condition of the target community; namely by holding a meeting with the Principal of SDN 10 Ciamis, namely Mrs. Iis Rohaeti S.Pd.

- Socialization Stage

In this stage, the service team will provide and explain the service plan that will be carried out so that time and various technical needs can be arranged in connection with the overall implementation of the training.

- Implementation Stage

The implementation of community service is carried out in collaboration with the State Elementary School 10 Ciamis. The lecture method was chosen to convey concepts about the environment, waste classification, women's participation in environmental management, and household waste management with the composting method. , inorganic and B3 for a brighter future.

\section{Results and Discussion}

This Community Service (PKM) activity was carried out at SDN 10 Ciamis, Jalan Ir.H. Juanda No 272, Ciamis District, Ciamis Regency, West Java, which with the implementation of this socialization is fully supported by the principal of SDN 10 Ciamis by giving permission to provide education to increase sales using social media. The activity was opened by giving an overview of waste in the surrounding environment, which began with an introduction to waste, especially waste in the surrounding environment, both in the school environment and the home environment. High school students are also invited to get to know what types and categories of waste exist in the surrounding environment. The process of sorting inorganic, organic and hazardous waste at SDN 10 Ciamis can be seen in Figure 3.

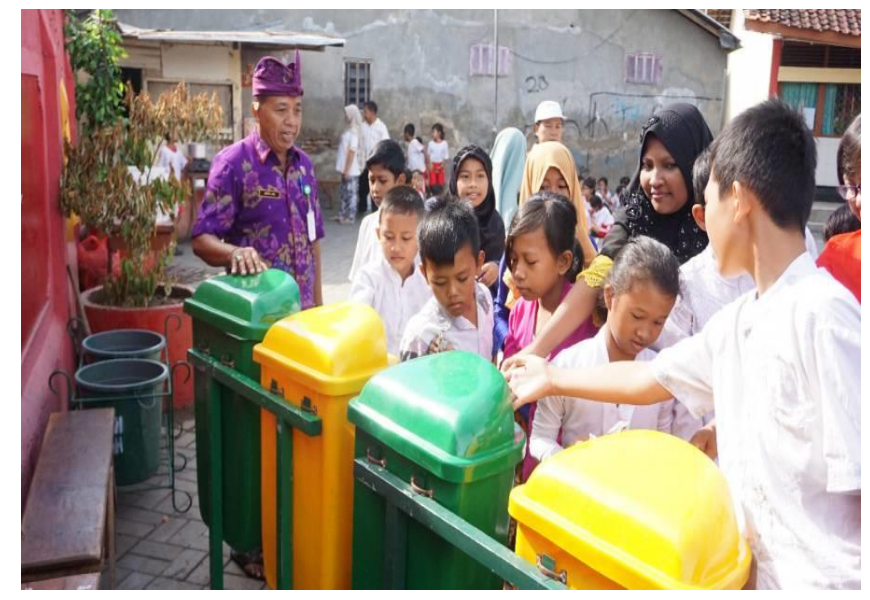

Figure 3 Process of sorting inorganic, organic and hazardous waste at SDN 10 Ciamis 
Furthermore, there will be a presentation about waste in the surrounding environment and the dangers of garbage accumulation for the environment by the team, namely Devi Sugianti, then for this second session, students are given an explanation about the types and categories of waste in the surrounding environment and students are given education Regarding the proper and correct method of sorting, processing and reducing waste, students are also given an explanation of the dangers of waste and natural damage that can occur if the waste is not managed properly. The next activity was the screening of a documentary film about the dangers of waste, in this session the participants were given an overview in the form of a film about the dangers of waste that threatens nature and an illustration of how to reduce waste so that natural damage does not occur due to the dangers of waste. The end of the documentary screening.

The activity continued with a Focus Group Discussion which was packaged with the theme of the game, namely grouping the types of waste and sorting which was moderated by Andi Gunawan, the participants who will take part in this game were divided into 3 groups, each group was given a picture of the types of waste and each group must classify what types and categories of waste are included into organic, inorganic, and B3 waste (hazardous and toxic waste) correctly and how to sort it out. Then enter the last event in the form of a review and distribution of door prizes by seeing which groups succeeded in choosing waste according to type and category, as well as sorting it out. After that, each group will receive a door prize to appreciate their participation in this game.

The service program in the form of education for sorting waste with this method needs to be continuously pursued considering the increasing production of waste in the school and home environment. This is due to the low awareness of the 3Rs, namely reuse (reusing used goods that can still be used), reduce (try to reduce waste), and recycle (recycle waste so that it can be used). In order to find a proper solution to the waste problem, in this service activity, training on classifying types of waste is taught as early as possible and starts with the school environment.

From the events that have been carried out, the results obtained are increasing knowledge in the form of an understanding of how to sort and treat waste properly and how to reduce waste so that pollution and environmental damage do not occur. This event is also one of the efforts to prevent natural damage due to irregular and indiscriminate disposal of waste.

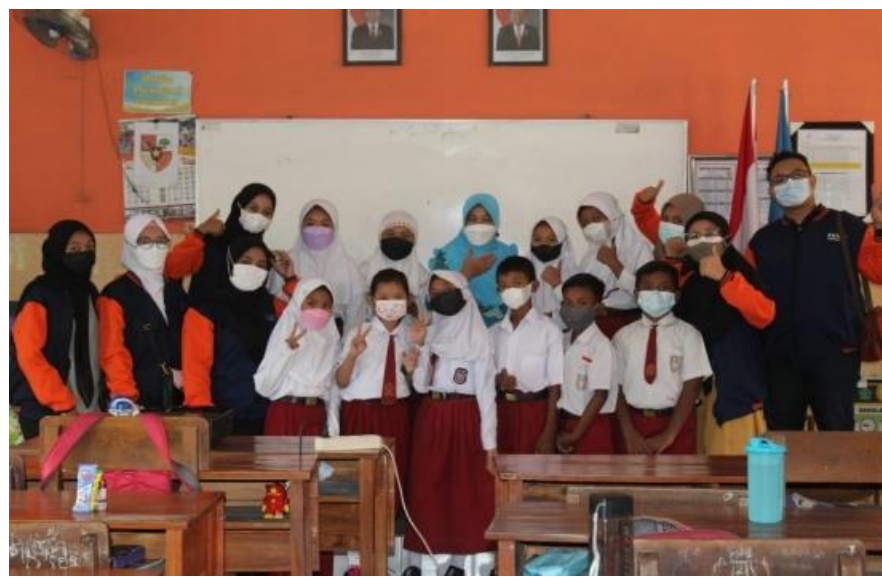

Figure 4. Group photo with participants from SDN 10 Ciamis

Overall, the training activities for managing waste in the surrounding environment, especially schools, using the lecture method and FGD (Focus Group Discussion) were considered successful (See Figure 4). This success is measured in addition to the suitability of the planned delivery schedule for educational materials with the implementation process. In addition, the target of understanding the material that has been given to participants, which is assessed from filling out the questionnaire, has also been successfully delivered. The understanding achieved includes the types and categories of waste, how to process waste, to the dangers that can arise from the presence of waste in the surrounding environment.

\section{Conclussion}

Based on the results that have been obtained from this community service program, the participants in the training have increased knowledge and skills in sorting waste so that the impact of environmental damage can be minimized. types and categories of waste, methods of processing waste, to the dangers that can arise from the presence of waste in the surrounding environment. 


\section{References.}

Chakrabarti, S., Majumder, A., \& Chakrabarti, S. (2009). Public-community participation in household waste management in India: An operational approach. Habitat International, 33(1), 125-130.

Derqui, B., \& Fernandez, V. (2017). The opportunity of tracking food waste in school canteens: Guidelines for self-assessment. Waste management, 69, 431-444.

Dhokhikah, Y., Trihadiningrum, Y., \& Sunaryo, S. (2015). Community participation in household solid waste reduction in Surabaya, Indonesia. Resources, Conservation and Recycling, 102, 153-162.

Grodzińska-Jurczak, M. (2003). The relation between education, knowledge and action for better waste management in Poland. Waste management \& research, 21(1), 2-18.

Gusti, A. (2016). The relationship of knowledge, attitudes, and behavioral intentions of sustainable waste management on primary school students in city of Padang, Indonesia. International Journal of Applied Environmental Sciences, 11(5), 1323-1332.

Khalil, M., Berawi, M. A., Heryanto, R., \& Rizalie, A. (2019). Waste to energy technology: The potential of sustainable biogas production from animal waste in Indonesia. Renewable and Sustainable Energy Reviews, 105, 323-331.

Kim, S. H., Kwak, T. K., Choi, E. H., \& Lee, K. E. (2007). Food waste management practices and influencing factors at elementary school food services. Korean Journal of Community Nutrition, 12(6), 815-825.

Meidiana, C., \& Gamse, T. (2010). Development of waste management practices in Indonesia. European journal of scientific research, 40(2), 199-210.

Moh, Y. (2017). Solid waste management transformation and future challenges of source separation and recycling practice in Malaysia. Resources, Conservation and Recycling, 116, 1-14.

Pandebesie, E. S., Indrihastuti, I., Wilujeng, S. A., \& Warmadewanthi, I. D. A. A. (2019). Factors influencing community participation in the management of household electronic waste in West Surabaya, Indonesia. Environmental Science and Pollution Research, 26(27), 27930-27939.

Paul, J. G., Arce-Jaque, J., Ravena, N., \& Villamor, S. P. (2012). Integration of the informal sector into municipal solid waste management in the Philippines-What does it need?. Waste Management, 32(11), 2018-2028.

Phan Hoang, T. T., \& Kato, T. (2021). Measuring the impact of solid waste management workshop activities in elementary schools: a six-month case study in Da Nang city, Vietnam. Applied Environmental Education \& Communication, 20(3), $238-255$.

Posmaningsih, S., Aryasih, S. K. M., Made, I. G. A., Choirul Hadi, M., Marwati, S. P., \& Mallongi, A. (2018). The influence of media booklet in behavior change of waste management in elementary school students, South Denpasar, Bali. Indian Journal of Public Health Research \& Development, 9(8), 1506-1511.

Raharjo, S., Matsumoto, T., Ihsan, T., Rachman, I., \& Gustin, L. (2017). Community-based solid waste bank program for municipal solid waste management improvement in Indonesia: a case study of Padang city. Journal of Material Cycles and Waste Management, 19(1), 201-212.

Ryu, G., Gwak, D. G., \& Choe, E. H. (2001). Assessment of waste management practices, source-reduction programs and related tasks in elementary school foodservice in Seoul and Kyonggi province areas. Journal of the Korean Dietetic Association, $7(4), 410-425$.

Sasaki, S., Araki, T., Tambunan, A. H., \& Prasadja, H. (2014). Household income, living and working conditions of dumpsite waste pickers in Bantar Gebang: Toward integrated waste management in Indonesia. Resources, conservation and recycling, $89,11-21$

Sekito, T., Prayogo, T. B., Dote, Y., Yoshitake, T., \& Bagus, I. (2013). Influence of a community-based waste management system on people's behavior and waste reduction. Resources, Conservation and Recycling, 72, 84-90.

Singer, J., Kieu, K. T., \& Pravitasari, A. E. (2019). Solid Waste Management in Tourist Destinations in Developing Nations: Case Studies in Hoi An, Vietnam, and Puncak, Indonesia. In Environmental Sustainability and Education for Waste Management (pp. 189-206). Springer, Singapore. 